With compliments of the Author 


\title{
1,3-Oxazinan-2-ones from Amines and 1,3-Diols through Dialkyl Carbonate Chemistry
}

\author{
Con Robert McElroy, Fabio Aricò, Pietro Tundo* \\ Università Ca' Foscari di Venezia, Dipartimento Scienze Ambientali, Informatica e Statistica, Dorsoduro 2137, 30123 Venice, Italy \\ Fax +39(041)2348620; E-mail: tundop@unive.it
}

Received: 16.01.2012; Accepted after revision: 19.04.2012

\begin{abstract}
A one-pot green synthesis of 1,3-oxazinan-2-ones from amines and 1,3-diols in the presence of a dialkyl carbonate and potassium tert-butoxide is described. Four dialkyl carbonates were utilised: dimethyl carbonate, diethyl carbonate, diprop-2-yl carbonate, and tert-butyl methyl carbonate. The more hindered the dialkyl carbonate used, the higher the yield of 1,3-oxazinan-2-one. Four 1,3diols were reacted having primary-primary, primary-secondary, primary-tertiary, and secondary-tertiary functionalities, with the yield of oxazinanone decreasing with increasing hindrance of the diol. In the case of the diols containing primary and either secondary or tertiary functionality, the substituent(s) were selectively found in the 6-position of the so-formed oxazinanone. The optimized conditions were then employed with different nucleophiles, namely phenylhydrazine, aniline, and $n$-octylamine.
\end{abstract}

Key words: green chemistry, cyclisation, heterocycles, diols, dialkyl carbonates

1,3-Oxazinan-2-ones (Figure 1) are compounds of great interest due to their biological activity. In fact, recently, they have appeared in numerous patents as intermediates in the synthesis of pharmaceutical drugs used in the treatment of Alzheimer, ${ }^{1}$ diseases mediated by the activation of $\beta 3$-adrenoceptorother, ${ }^{2}$ diseases related to kinases activity, ${ }^{3}$ and for the regulation of cholesterol. ${ }^{4}$ They are also used as herbicides with excellent crop-weed selectivity. ${ }^{5}$

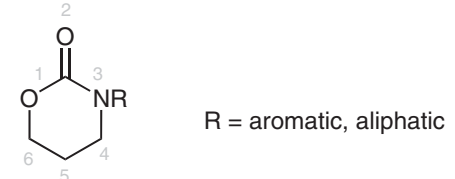

Figure 1 The 1,3-oxazinan-2-one motif

There are many routes to 1,3-oxazinan-2-ones, the majority involve phosgene and isocyanate ${ }^{6}$ or alkyl halide ${ }^{7}$ chemistry, while those that are considered green routes either require not easy available starting materials ${ }^{8}$ or mul- tiple steps. ${ }^{9}$ Recently, our group described a new route to 1,3-oxazinan-2-ones, via the two-step reaction of a primary amine or phenylhydrazine with a dicarbonate derivative of 1,3-diols synthesised by dimethyl carbonate (DMC) chemistry (Scheme 1$) ;{ }^{10}$ the latter being an established green reagent. ${ }^{11}$ The reaction mechanism was discussed representing the first example of a carbonate reacting selectively and sequentially, firstly at the carbon$\mathrm{yl}$ centre to form a linear carbamate and then as a leaving group to yield a cyclic carbamate.

In this paper, the cyclisation reaction is performed in onestep by synthesising the bis(dialkyl)propane-1,3-diyldicarbonate in situ, through a cascade reaction (Scheme 2); the general application of this methodology and the influence on the yield of differently substituted 1,3-diols and dialkyl carbonates (DAC) were investigated. The synthesis was carried out on different nucleophiles, that is, aliphatic and aromatic amines and phenylhydrazine.

All reactions followed Scheme 3 where substituents $R^{1}$, $\mathrm{R}^{2}$, and $\mathrm{R}^{3}$ are selected so to modify the functionality of the 1,3-diol. DAC selected for this study were DMC, diethyl carbonate (DEC), diprop-2-yl carbonate (Di-PrC) and tert-butyl methyl carbonate $(\mathrm{M} t-\mathrm{BuC})$.

The unsymmetrical carbonate $\mathrm{M} t-\mathrm{BuC}$ was used instead of the di-tert-butyl carbonate as the latter is too sterically hindered for any reaction to occur. ${ }^{12}$

The base selected was potassium tert-butoxide as it gave the best results, although other alkoxides (sodium methoxide) are also efficient bases, but gave lower yields. Carbonate derivatives of the 1,3-diols having the tertbutoxy functionality were present in all the reaction mixtures, but only in small amounts.

For this study a primary amine, benzylamine, was selected as substrate. It is noteworthy that the reactions do not require the presence of a solvent.

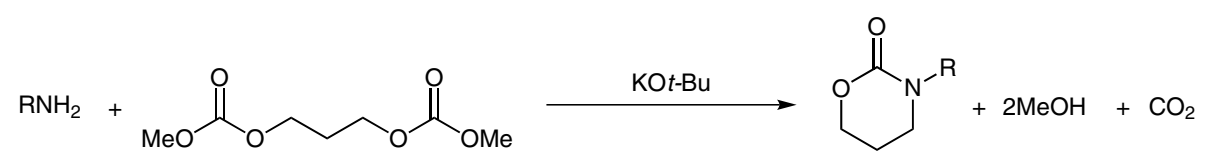

Scheme 1 Intermolecular cyclisation of an amine with dimethyl propane-1,3-diyl-dicarbonate ${ }^{10}$

SYNLETT 2012, 23, 1809-1815

Advanced online publication: 29.06 .2012

DOI: 10.1055/s-0031-1290368; Art ID: ST-2012-D0042-L

(C) Georg Thieme Verlag Stuttgart · New York 


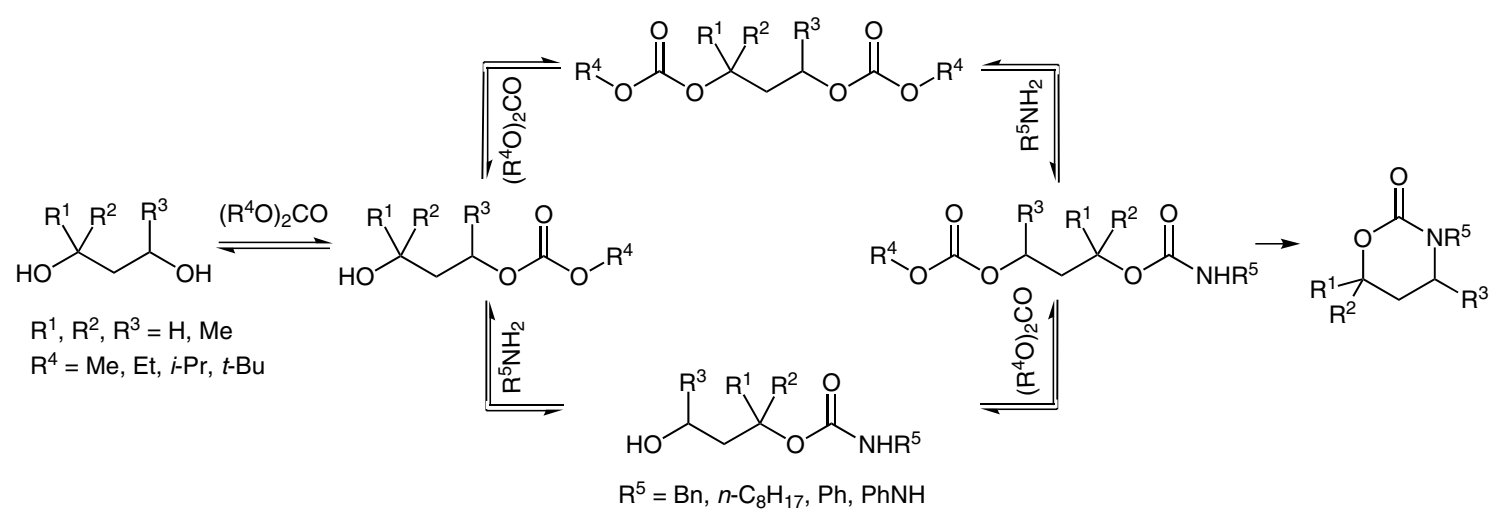

Scheme 2 An example of in situ cascade reaction to an 1,3-oxinan-2-one described in this paper; all reactions are equilibriums with exception of the final cyclisation step

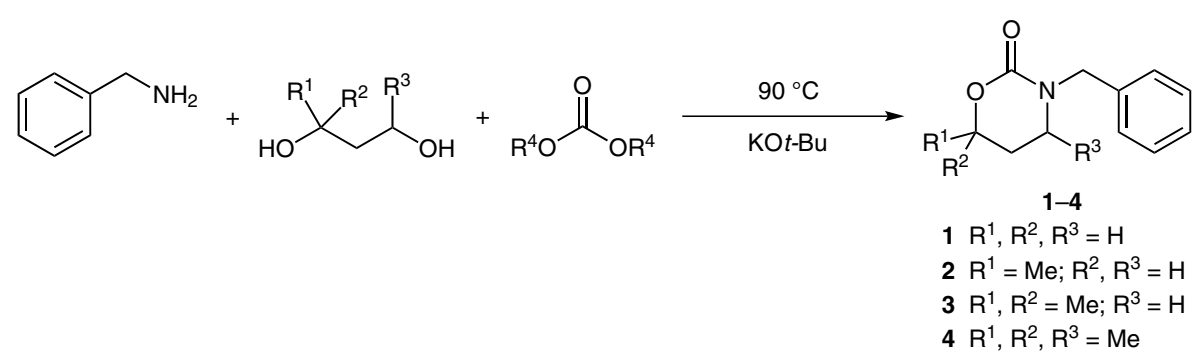

Scheme 3 Synthesis of 1,3-oxazinan-2-ones via DAC chemistry

Benzylamine was reacted with propane-1,3-diol in the presence of different DAC to give 3-benzyl-1,3-oxazinan2-one 1 (Scheme 3). As propane-1,3-diol contains two primary alcohols with identical reactivity, the sole variable is the DAC used. The results are reported in Table 1.

When DMC or DEC were employed, 3-benzyl-1,3-oxazinan-2-one (1) was isolated in $21 \%$ and $36 \%$ yield, respectively (Table 1 , entries 1 and 2). In our previous paper, ${ }^{10}$ the reaction of dimethyl propane-1,3-diyl-dicarbonate with benzylamine (Scheme 1) gave an isolated yield of oxazinanone 1 of $40 \%$. However, when the reactions were carried out utilising $\mathrm{D} i$-PrC and $\mathrm{M} t$-BuC (Table 1, entries 3 and 4) oxazinanone 1 was isolated in higher yields than those achieved employing the presynthesised bis(dialkylcarbonate) in a two-step reaction. It is noteworthy that in the reaction depicted in Scheme 3, only three equivalents

Table 1 Reaction of Benzylamine with 1,3-Propanediol in the Presence of a DAC and Potassium tert-Butoxide to Yield Oxazinone $\mathbf{1}^{\text {a }}$

Entry

\footnotetext{
${ }^{a}$ All reactions were carried out at $90{ }^{\circ} \mathrm{C}$ for $2 \mathrm{~h}$, in the absence of a solvent with a 1.0:1.0:2.0:3.0 molar ratio of benzylamine/diol/base/DAC, respectively. Due to the large number of parasitic reactions and their related products, HPLC data has not been calibrated, as to isolate every byproduct would be too complex.
} 
of DAC are required to yield oxazinanone $\mathbf{1}$, and no solvent is used. The reduced amount of reagents/solvents represents a significant saving in terms of reaction volume, energy usage, and consumption of reagents.

Table 1 shows a significant trend in increasing yield of cyclic product from entriy 1 through to entry 4 . The formation of the oxazinanone $\mathbf{1}$ is the consequence of a cascade reaction (Scheme 2) that requires both alcohol and amine functionalities to react with the DAC through a $\mathrm{B}_{\mathrm{Ac}} 2$ pathway. Due to the many consecutive steps involved and the different DAC utilized, it is not easy to compare the different reaction pathways and intermediates from entries 1-4 and thus to clearly justify the trend in yields observed.

It is already known, however, that, when reacting an amine with a DAC in the presence of a base, the more hindered the DAC, the easier the formation of a carbamate, as more hindered alcoxides are better leaving groups. ${ }^{13}$ Conversely, when an alcohol is reacted with a DAC in basic conditions the trend of the leaving group is almost the reverse of that observed with an amine. ${ }^{14}$

Although it is not the objective of this paper to investigate the reaction mechanism, the results shown here seem to be in good agreement with the previous observations ${ }^{13,14}$ even if the presence of many equilibrium reactions makes the question not easy to clarify.

The cyclisation reaction was then investigated employing butane-1,3-diol that incorporates primary and secondary functionalities. In this case the product formed is 3-benzyl-6-methyl-1,3-oxazinan-2-one (2). The aim is to observe the effect, if any, of the influence of steric factors of the substrate on the synthesis of the oxazinanone 2 . The results are reported in Table 2.

The trend of increasing yield of the cyclic product when utilising more hindered DAC is similar to the one seen in
Table 1. It is noteworthy that the reaction of benzylamine with the presynthesised dimethyl 3-methylpropane-1,3diyl-dicarbonate gave the 1,3-oxazinan-2-one 2 in only $18 \%$ yield. ${ }^{10}$ On the other hand, employing the one-pot synthetic approach and more hindered DAC (Table 2, entries 2-4), oxazinanone 2 was isolated in better yields up to $45 \%$.

Significantly, ${ }^{1} \mathrm{H}$ NMR analysis of the cyclic product synthesised confirmed that the methyl group is exclusively located in the 6-position of the oxazinanone ring. This suggests that intramolecular attack on the soft electrophilic centre of the carbonate functionality ( $\mathrm{B}_{\mathrm{Al}} 2$ pathway) preferentially occurs on a $\mathrm{CH}_{2}$ group (Scheme 4). As a consequence, this cyclisation reaction results in high selectivity towards substituents in the 6- and not in the 4position of the oxazinanone ring.<smiles>[Y6]c1cccc(CN2CC(C)CCOC2=O)c1</smiles>

Scheme 4 Selectivity towards 6-methyl oxazinanones

Accordingly, in the case of butane-1,3-diol only one reaction pathway selectively leads to the formation of the oxazinanone, so a much lower yield of the cyclic product would be expected. However, the yields observed in Table 2 are not dramatically lower than those in Table 1; this

Table 2 Reaction of Benzylamine with Butane-1,3-diol in the Presence of a DAC and Potassium tert-Butoxide to Yield Oxazinone $\mathbf{2}^{\mathrm{a}}$

\begin{tabular}{|c|c|c|c|c|}
\hline Entry & DAC & Conv. $(\%)$ & HPLC yield (area, \%) & Isolated yield $(\%)$ \\
\hline 1 & & 98 & 28 & 14 \\
\hline 2 & & 98 & 39 & 27 \\
\hline 3 & & 98 & 46 & 44 \\
\hline 4 & & 96 & 51 & 45 \\
\hline
\end{tabular}

${ }^{a}$ All reactions were carried out at $90^{\circ} \mathrm{C}$ for $2 \mathrm{~h}$, in the absence of a solvent with a 1.0:1.0:2.0:3.0 molar ratio of benzylamine/diol/base/DAC, respectively. Due to the large number of parasitic reactions and their related products, HPLC data has not been calibrated, as to isolate every byproduct would be too complex. 
Table 3 Reaction of Benzylamine with 3-Methylbutane-1,3-diol in the Presence of a DAC and Potassium tert-Butoxide to Yield Oxazinanone $3^{\mathrm{a}}$

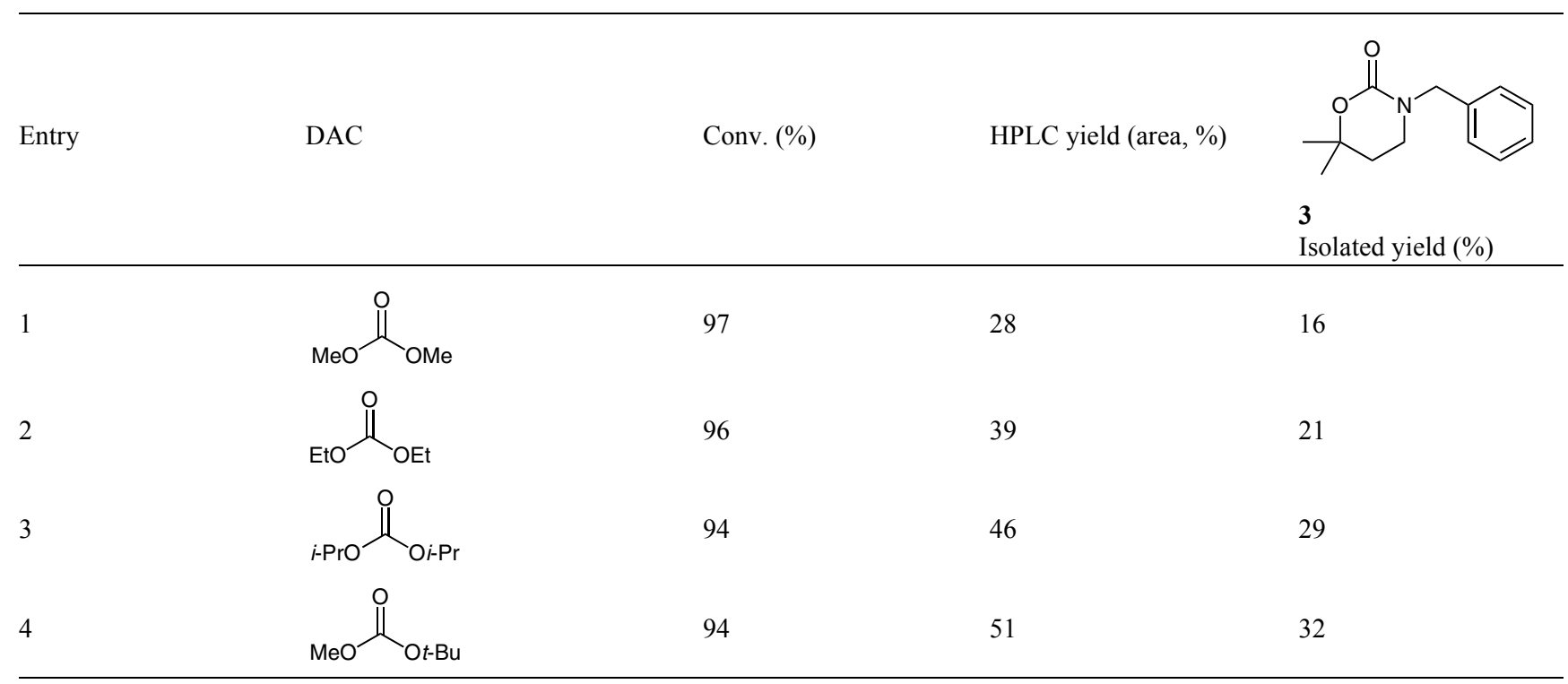

${ }^{a}$ All reactions were carried out at $90^{\circ} \mathrm{C}$ for $2 \mathrm{~h}$, in the absence of a solvent with a 1.0:1.0:2.0:3.0 molar ratio of benzylamine/diol/base/DAC, respectively. Due to the large number of parasitic reactions and their related products, HPLC data has not been calibrated, as to isolate every byproduct would be too complex.

might be attributed to the reversible nature of the cascade reactions leading up finally to the formation of the product 2 (Scheme 2). As the compound $\mathbf{5}$ is consumed, while $\mathbf{6}$ is not, the concentration gradient might push the equilibrium of a number of reactions to give more of the intermediate which leads irreversibly to the oxazinanone 2 .

Finally, it must be mentioned that the presence of the secondary alcohol does effect, to an extent, the yields of oxazinanone 2 being lower than those of oxazinanone $\mathbf{1}$.

Benzylamine was then reacted with 3-methylbutane-1,3diol, containing primary and tertiary functionalities, in the presence of a DAC and the base to give 3-benzyl-6,6-dimethyl-1,3-oxazinan-2-one (3).

The results, reported in Table 3 confirmed once again the influence of the steric factors previously observed.

Due to the difficulty in isolating 3-benzyl-6,6-dimethyl1,3-oxazinan-2-one (3), for this set of reactions only the HPLC data has been scrutinised. ${ }^{15}$

The same trend of increasing yield with increasing steric hindrance of the DAC previously observed in Tables 1 and 2 , is also seen in Table 3 . The yields for oxazinone 3 are lower compared to those observed for oxazinanones 1 and $\mathbf{2}$, most likely as a result of the low reactivity of the tertiary alcohol in transesterification reactions. Also in this case, ${ }^{1} \mathrm{H}$ NMR confirmed that the two methyl substituents are solely in the 6-position.

To further support the results observed the diol 2-methylpentane-2,4-diol was reacted with benzylamine and $\mathrm{M} t$ $\mathrm{BuC}$ in the presence of potassium tert-butoxide to give 3benzyl-4,6,6-trimethyl-1,3-oxazinan-2-one (4). The Mt$\mathrm{BuC}$ was selected as in the previous reactions. It has been shown to give the highest yield of oxazinanone.
In this case, analysis of the reaction by GC-MS indicated that the major product was methyl $N$-benzylcarbamate most likely as a result of the steric hindrance both of the diol and of the $\alpha$-carbon in the intramolecular cyclisation step (Scheme 4). A very small yield of cyclic product $\mathbf{4}$ was detected $(0.3 \%) .{ }^{16}$ Therefore nucleophilic displacement of the carbonate group upon attack of a hindered carbon is probably not energetically favored. This confirms that cyclisation occurs preferably via intramolecular nucleophilic attack on a $\mathrm{CH}_{2}$ group (Scheme 2).

The general applicability of the one-pot synthesis to 1,3oxazinan-2-ones was then investigated employing several nucleophiles, that is, aniline, phenylhydrazine, and $n$-octylamine. These substrates were reacted with differently substituted 1,3-diols in the presence of the preferred DAC, $\mathrm{M} t$-BuC, (Scheme 5).

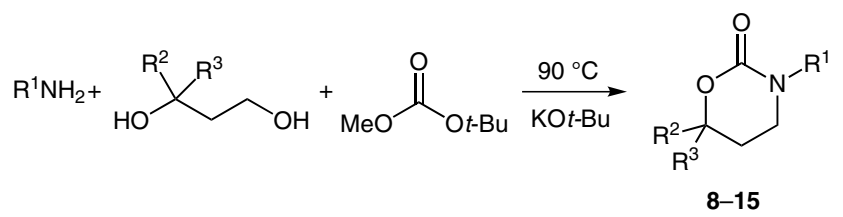

$$
\begin{aligned}
& 8 \mathrm{R}^{1}=\mathrm{Ph} ; \mathrm{R}^{2}, \mathrm{R}^{3}=\mathrm{H} \quad 12 \mathrm{R}^{1}=\mathrm{PhNH} ; \mathrm{R}^{2}=\mathrm{Me} ; \mathrm{R}^{3}=\mathrm{H} \\
& 9 \mathrm{R}^{1}=\mathrm{Ph} ; \mathrm{R}^{2}=\mathrm{Me} ; \mathrm{R}^{3}=\mathrm{H} 13 \mathrm{R}^{1}=\mathrm{PhNH} ; \mathrm{R}^{2}, \mathrm{R}^{3}=\mathrm{Me} \\
& 10 R^{1}=\mathrm{Ph} ; \mathrm{R}^{2}, \mathrm{R}^{3}=\mathrm{Me} \quad 14 \mathrm{R}^{1}=\text { Oct; } \mathrm{R}^{2}, \mathrm{R}^{3}=\mathrm{H} \\
& 11 \mathrm{R}^{1}=\mathrm{PhNH} ; \mathrm{R}^{2}=\mathrm{R}^{3}=\mathrm{H} \quad 15 \mathrm{R}^{1}=\mathrm{Oct} ; \mathrm{R}^{2}=\mathrm{Me} ; \mathrm{R}^{3}=\mathrm{H}
\end{aligned}
$$

Scheme 5 Reaction of a 1,3-diol with an amine or phenylhydrazine to give the 1,3-oxazinan-2-ones $\mathbf{8}-\mathbf{- 1 5}$

Table 4 shows that this cascade synthetic approach to oxazinanones can be employed efficiently to several amines and also to phenylhydrazine, giving adequate to good 
Table 4 Reaction of Amines and Phenylhydrazine with a 1,3-Diol in the Presence of Methyl tert-Butyl Carbonate with Potassium tert-Butoxide ${ }^{\mathrm{a}}$

\begin{tabular}{lllll}
\hline Entry & Nucleophile & Diol & GC-MS area (\%) & Isolated yield (\%) \\
\hline 1 & aniline & propane-1,3-diol & 46 & $\mathbf{8 3 4}$ \\
2 & aniline & butane-1,3-diol & 62 & $\mathbf{9 4} 41$ \\
3 & aniline & 3-methylbutane-1,3-diol & 34 & $\mathbf{1 0 3 2}$ \\
4 & phenylhydrazine & propane-1,3-diol & 61 & $\mathbf{1 1 2 4}$ \\
5 & phenylhydrazine & butane-1,3-diol & 76 & $\mathbf{1 2} 53$ \\
6 & phenylhydrazine & 3-methylbutane-1,3-diol & 52 & $\mathbf{1 3} 18$ \\
7 & $n$-octylamine & propane-1,3-diol & 51 & $\mathbf{1 4 2 5}$ \\
8 & $n$-octylamine & butane-1,3-diol & 32 & $\mathbf{1 5} 17$ \\
\hline
\end{tabular}

${ }^{a}$ All reactions were carried out at $90{ }^{\circ} \mathrm{C}$ for $2 \mathrm{~h}$, in the absence of a solvent with a 1.0:1.0:2.0:3.0 molar loading of amine/phenylhydrazine/di$\mathrm{ol} /$ base/dialkyl carbonate, respectively. Due to the large number of parasitic reactions and their resultant products for each entry, the HPLC data has not been calibrated, as to isolate every byproduct would be too complex.

yields. Notably oxazinanones $\mathbf{9}$ and $\mathbf{1 2}$ were achieved in $62 \%$ and $76 \%$ yields, respectively (according to GC-MS).

In particular, while $n$-octylamine follows a similar trend to that of benzylamine in terms of decreasing yield as the hindrance of the diol increases, aniline and phenylhydrazine showed a different trend. This is possibly a result of steric hindrance between the rigid aromatic system of the amine/hydrazine and the methyl group(s) on the carbon $\alpha$ to the carbamate. In all cases, ${ }^{1} \mathrm{H}$ NMR analysis of the oxazinanones confirmed that methyl substituent(s) were found solely in the 6-position.

Table 4 shows a disparity between the observed and isolated yields since products $\mathbf{8}-\mathbf{1 3}$ were isolated by crystallisation and not by column chromatography as in Tables $1-3$, thus, it is expected that a certain amount of the compounds remain within the liquor. Also, in the case of oxazinanones 7-9 the large hydrophobic chain present in the compound made its separation from other byproducts via column chromatography somewhat difficult.

In conclusion, a one-pot synthesis of oxazinanones from amines or phenyl hydrazine, 1,3-diols and DAC through a cascade reaction in the presence of a base and without any solvent has been described. According to the results obtained we can make several observations on this novel synthetic approach to 1,3-oxazinan-2-ones:

Structure of the 1,3-Diol. A very high level of selectivity is found when reacting a 1,3-diol with both primary functionality and a substituent $\alpha$ to the other $\mathrm{OH}$ group. For cyclisation to occur through nucleophilic displacement, primary $\mathrm{CH}_{2}$ functionality $\alpha$ to the carbonate must be present, as substituents on the oxazinanone ring are found in the 6-position, never in the 4-position. Comparing the results from Tables $1-4$, it is evident that in the case of aliphatic amines, the more hindered the diol the lower the yield of oxazinanone.

Structure of the DAC. The role of the DAC in the cascade cyclisation reaction is multifunctional. They act as leaving groups, entering groups and protecting groups. Comparing the results from entries 1-4 in each Table, the more hindered the DAC the greater the yield of oxazinaone observed.

One-Pot Reaction. Synthesising the 1,3-dicarbonate in situ removes a lengthy step from the production of the oxazinanone, requires far less equivalents of DAC and reduces the energy consumption for the process. This onepot reaction has many variables: temperature, reaction time, base, 1,3-diol, DAC, and amine. The present work has established the effect of DAC and 1,3-diols on the reaction yields; it should be noted that the latter are already definitely higher than those previously reported in the literature. However, reaction conditions such as different DAC, time, temperature, and base should be investigated individually for each novel 1,3-oxazin-2-ones in order to achieve optimised yields.

\section{Experimental Data}

All experimental procedures described were carried out under air and in oven-dried glassware. All reagents were ACS grade and were employed without further purification. Alkyl carbamates DPrC and $\mathrm{M} t$-BuC were synthesised and purified as described in our previous paper. ${ }^{14}{ }^{1} \mathrm{H}$ NMR and ${ }^{13} \mathrm{C}$ NMR spectra were obtained on a Bruker AVANCE 300 spectrometer at $25^{\circ} \mathrm{C}$ and referred to deuterated $\mathrm{CHCl}_{3}$ as internal standard. Melting point analyses carried out are uncorrected. HPLC analyses were carried out at $20^{\circ} \mathrm{C}$ on a $\mathrm{C} 185$ $\mu \mathrm{m}$ column $(4.6 \times 150 \mathrm{~mm})$ using an eluting system of acidified $\mathrm{H}_{2} \mathrm{O}-\mathrm{MeCN}(65: 35)$ at $0.8 \mathrm{~mL} / \mathrm{min}$ and detecting at $\lambda=210 \mathrm{~nm}$. A typical sample size was $100 \mu \mathrm{L}$ of a solution comprising of $0.1 \mathrm{~g}$ of the reaction mixture, $5 \mathrm{~mL}$ of $18.8 \mathrm{mM}$ solution of nitrobenzene in $\mathrm{MeCN}$ as standard, and $20 \mathrm{~mL}$ of $\mathrm{MeCN}-\mathrm{H}_{2} \mathrm{O}$ (50:50). GC-MS analyses were performed at $70 \mathrm{eV}(\mathrm{MS})$ with a $30 \mathrm{~m}$ HP 5 capillary GC column. A typical sample size was $0.2 \mu \mathrm{L}$ of a solution of $1 \mathrm{mg}$ of the reaction mixture in $1 \mathrm{~mL}$ of $\mathrm{CH}_{2} \mathrm{Cl}_{2}$.

\section{General Synthesis of an 1,3-Oxazinan-2-one}

To an oven dried $50 \mathrm{~mL}$ round-bottom flask equipped with a magnetic stirrer bar and condenser was added the amine/hydrazine (10 $\mathrm{mmol})$, the $1,3 \mathrm{diol}(10 \mathrm{mmol})$, and the required alkyl carbonate$\operatorname{DMC}(2.7 \mathrm{~g}, 30 \mathrm{mmol}), \operatorname{DEC}(3.54 \mathrm{~g}, 30 \mathrm{mmol}), \operatorname{DPrC}(4.38 \mathrm{~g}, 30$ 
mmol), or $\mathrm{M} t-\mathrm{BuC}(3.96 \mathrm{~g}, 30 \mathrm{mmol})$, which were reacted at $90{ }^{\circ} \mathrm{C}$ for $2 \mathrm{~h}$ in the presence of $\mathrm{KO} t$-Bu $(2.24 \mathrm{~g}, 20 \mathrm{mmol})$. The reaction was then quenched with $\mathrm{H}_{2} \mathrm{O}(5 \mathrm{~mL})$ and the mixture extracted with $\mathrm{CH}_{2} \mathrm{Cl}_{2}(2 \times 10 \mathrm{~mL})$, dried over $\mathrm{Na}_{2} \mathrm{SO}_{4}$ and the solvent removed under vacuum to give a yellow/orange oil, which was further purified depending upon the product.

\section{Additional Purification for 1, 2, and 14}

The oil was then purified via column chromatography on silica using $\mathrm{Et}_{2} \mathrm{O}$ to remove the byproducts and then $\mathrm{MeOH}$ to give the product.

\section{Additional Purification for 3 and 15}

The oil was then purified via column chromatography on silica using $\mathrm{Et}_{2} \mathrm{O}$-cyclohexane $(1: 1)$ to give adequate separation of the byproducts and the product.

\section{Purification for 8-13}

The product was then precipitated out in $\mathrm{Et}_{2} \mathrm{O}$ and recrystallised in PrOH.

Spectroscopic data for products $\mathbf{1}, \mathbf{8}$, and $\mathbf{1 1}$ has previously been reported. ${ }^{10}$

\section{3-Benzyl-1,3-oxazinan-2-one (1)}

The product was recrystallised in $\mathrm{Et}_{2} \mathrm{O}$ to give a white crystalline solid (DMC: $0.402 \mathrm{~g}, 2.09 \mathrm{mmol}$, yield 21\%; DEtC: $0.684 \mathrm{~g}, 3.58$ mmol, yield 36\%; Di-PrC: 0.892 g, 4.67 mmol, yield 47\%; MCt-Bu: $1.086 \mathrm{~g}, 5.69 \mathrm{mmol}$, yield 57\%).

\section{3-Benzyl-6-methyl-1,3-oxazinan-2-one (2)}

The product was recrystallised in $\mathrm{Et}_{2} \mathrm{O}\left(\right.$ at $\left.-18^{\circ} \mathrm{C}\right)$ to give a yellow crystalline solid (DMC: $0.284 \mathrm{~g}, 1.39 \mathrm{mmol}$, yield 14\%; DEtC: $0.563 \mathrm{~g}, 2.75 \mathrm{mmol}$, yield 28\%; D $i$-PrC: $0.897 \mathrm{~g}, 4.38 \mathrm{mmol}$, yield 44\%; MCt-Bu: $0.928 \mathrm{~g}, 4.53 \mathrm{mmol}$, yield 45\%); mp 52.4-54.3 ${ }^{\circ} \mathrm{C}$. ${ }^{1} \mathrm{H}$ NMR (300 MHz, $\left.\mathrm{CDCl}_{3}\right): \delta=1.30-1.33(\mathrm{~d}, J=6.3 \mathrm{~Hz}, 3 \mathrm{H})$, 1.64-1.77 (m, 1 H), 1.87-1.95 (m, 1 H), 3.07-3.25 (m, 2 H), 4.28$4.38(\mathrm{~m}, 1 \mathrm{H}), 4.42-4.61(\mathrm{~m}, 2 \mathrm{H}), 7.22-7.32(\mathrm{~m}, 5 \mathrm{H}) .{ }^{13} \mathrm{C} \mathrm{NMR}$ $\left(75 \mathrm{MHz}_{\mathrm{CDCl}}\right): \delta=20.7,28.7,43.5,52.3,73.4,127.5,127.9$, 128.6, 136.7, 154.1. HRMS: $m / z$ calcd for $\mathrm{C}_{12} \mathrm{H}_{15} \mathrm{NO}_{2}+\mathrm{H}^{+}$. 206.1182; found: 206.1202 .

\section{3-Benzyl-6,6-dimethyl-1,3-oxazinan-2-one 3}

The product was then recrystallised in $\mathrm{Et}_{2} \mathrm{O}\left(-18^{\circ} \mathrm{C}\right)$ to give a white crystalline solid, mp 65.7-68.3 ${ }^{\circ} \mathrm{C} .{ }^{1} \mathrm{H}$ NMR $\left(300 \mathrm{MHz}, \mathrm{CDCl}_{3}\right): \delta$ $=1.36(\mathrm{~s}, 6 \mathrm{H}), 1.81-1.86(\mathrm{t}, J=6.5 \mathrm{~Hz}, 2 \mathrm{H}), 3.16-3.20(\mathrm{t}, J=6.4$ $\mathrm{Hz}, 2 \mathrm{H}), 4.57$ (s, $2 \mathrm{H}), 7.24-7.36$ (m, $5 \mathrm{H}) .{ }^{13} \mathrm{C} \mathrm{NMR}(75 \mathrm{MHz}$, $\left.\mathrm{CDCl}_{3}\right): \delta=27.0,32.4,41.5,52.3,78.0,127.5,127.9,128.6,136.8$, 153.7. HRMS: $m / z$ calcd for $\mathrm{C}_{13} \mathrm{H}_{17} \mathrm{NO}_{2}+\mathrm{H}^{+}$: 220.1338; found: 220.1354

\section{3-Phenyl-1,3-oxazinan-2-one (8)}

White crystalline product $(0.610 \mathrm{~g}, 3.41 \mathrm{mmol}$, yield $34 \%)$.

\section{6-Methyl-3-phenyl-1,3-oxazinan-2-one (9)}

White crystalline product $(0.791 \mathrm{~g}, 4.14 \mathrm{mmol}$, yield $41 \%)$; mp 78.3-78.6 ${ }^{\circ} \mathrm{C}$ (lit. ${ }^{6} 78-79{ }^{\circ} \mathrm{C}$ ). ${ }^{1} \mathrm{H}$ NMR $\left(300 \mathrm{MHz}, \mathrm{CDCl}_{3}\right): \delta=$ $1.47-1.49(\mathrm{~d}, J=6.3 \mathrm{~Hz}, 3 \mathrm{H}), 1.94-2.19$ (m, $2 \mathrm{H}), 3.62-3.82$ (m, 2 $\mathrm{H}), 4.53-4.64(\mathrm{~m}, 1 \mathrm{H}), 7.24-7.43(\mathrm{~m}, 5 \mathrm{H}) .{ }^{13} \mathrm{C} \mathrm{NMR}(75 \mathrm{MHz}$, $\left.\mathrm{CDCl}_{3}\right): \delta=21.4,29.7,48.5,74.5 .3,126.3,127.2,129.6,143.2$, 153.4 .

\section{6,6-Dimethyl-3-phenyl-1,3-oxazinan-2-one (10)}

White crystalline product $(0.654 \mathrm{~g}, 3.19 \mathrm{mmol}$, yield $32 \%), \mathrm{mp}$ 123.3-123.7 ${ }^{\circ} \mathrm{C} .{ }^{1} \mathrm{H}$ NMR $\left(300 \mathrm{MHz} \mathrm{CDCl}_{3}\right): \delta=1.51(\mathrm{~s}, 6 \mathrm{H})$, 2.03-2.07 (t, $J=6.4 \mathrm{~Hz}, 2 \mathrm{H}), 3.69-3.73(\mathrm{t}, J=6.4 \mathrm{~Hz}, 2 \mathrm{H}), 7.23$ $7.43(\mathrm{~m}, 5 \mathrm{H}) .{ }^{13} \mathrm{C} \mathrm{NMR}\left(75 \mathrm{MHz}, \mathrm{CDCl}_{3}\right): \delta=27.7,33.4,46.4$, 79.0.3, 126.4, 127.2, 129.7, 143.3, 153.1. HRMS: $\mathrm{m} / \mathrm{z}$ calcd for $\mathrm{C}_{12} \mathrm{H}_{15} \mathrm{NO}_{2}+\mathrm{Na}^{+}: 228.1964$; found: 228.1935 .

3-Phenylamino-1,3-oxazinan-2-one (11)

White crystalline product $(0.468 \mathrm{~g}, 2.44 \mathrm{mmol}$, yield $24 \%)$.
6-Methyl-3-phenylamino-1,3-oxazinan-2-one (12)

White crystalline product (1.092 g, $5.30 \mathrm{mmol}$, yield $53 \%$; mp 156.5-157.5 ${ }^{\circ} \mathrm{C} .{ }^{1} \mathrm{H}$ NMR $\left(300 \mathrm{MHz}, \mathrm{CDCl}_{3}\right): \delta=1.35-1.37(\mathrm{~d}, J=$ $6.3 \mathrm{~Hz}, 3 \mathrm{H}), 1.82-2.03(\mathrm{~m}, 2 \mathrm{H}), 3.39-3.46(\mathrm{~m}, 1 \mathrm{H}), 3.53-3.63$ (m, $1 \mathrm{H}), 4.37-4.44(\mathrm{~m}, 1 \mathrm{H}), 6.68-6.75(\mathrm{~m}, 3 \mathrm{H}) 6.82-6.86(\mathrm{t}, J=7.3$ $\mathrm{Hz}, 1 \mathrm{H}), 7.15-7.20(\mathrm{t}, J=8.2 \mathrm{~Hz}, 2 \mathrm{H}) .{ }^{13} \mathrm{C} \mathrm{NMR}(75 \mathrm{MHz}$, $\left.\mathrm{CDCl}_{3}\right): \delta=21.1,29.8,48.2,74.4,113.5,121.2,129.7,145.8$, 155.0. HRMS: $m / z$ calcd for $\mathrm{C}_{11} \mathrm{H}_{14} \mathrm{~N}_{2} \mathrm{O}_{2}+\mathrm{H}^{+}$: 207.1134; found: 207.1152 .

\section{6,6-Dimethyl-3-phenylamino-1,3-oxazinan-2-one (13)}

White crystalline product $(0.404 \mathrm{~g}, 1.84 \mathrm{mmol}$, yield $18 \%) ; \mathrm{mp}$ 184.3-185.0 ${ }^{\circ} \mathrm{C} .{ }^{1} \mathrm{H}$ NMR $\left(300 \mathrm{MHz}, \mathrm{CDCl}_{3}\right): \delta=1.47(\mathrm{~s}, 6 \mathrm{H})$, $2.01-2.06(\mathrm{t}, J=6.4 \mathrm{~Hz}, 2 \mathrm{H}), 3.63-3.67(\mathrm{t}, J=6.4 \mathrm{~Hz}, 2 \mathrm{H}), 6.71-$ $6.74(\mathrm{~d}, J=6.7 \mathrm{~Hz}, 2 \mathrm{H}), 6.86-6.91(\mathrm{t}, J=7.4 \mathrm{~Hz}, 1 \mathrm{H}), 7.19-7.26$ $(\mathrm{t}, J=7.5 \mathrm{~Hz}, 2 \mathrm{H}) .{ }^{13} \mathrm{C} \mathrm{NMR}\left(75 \mathrm{MHz}, \mathrm{CDCl}_{3}\right): \delta=27.6,33.6$, 46.4, 79.6, 113.7, 121.6, 129.8, 146.9, 154.3. HRMS: $m / z$ calcd for $\mathrm{C}_{12} \mathrm{H}_{16} \mathrm{~N}_{2} \mathrm{O}_{2}+\mathrm{H}^{+}$: 221.1290; found: 221.1306 .

\section{3-Octyl-1,3-oxazinan-2-one (14)}

Yellow oil (0.541 g, $2.54 \mathrm{mmol}$, yield 25\%). ${ }^{1} \mathrm{H}$ NMR (300 MHz, $\left.\mathrm{CDCl}_{3}\right): \delta=0.61-0.66(\mathrm{t}, J=6.4 \mathrm{~Hz}, 3 \mathrm{H}), 1.03-1.05(\mathrm{~m}, 10 \mathrm{H})$, $1.29-1.38$ (quin, $J=6.9 \mathrm{~Hz}, 2 \mathrm{H}$ ), $1.76-1.84$ (quin, $J=6.1 \mathrm{~Hz}, 2 \mathrm{H}$ ), 3.04-3.11 (m, $4 \mathrm{H}), 3.97-4.01(\mathrm{t}, J=5.3 \mathrm{~Hz}, 2 \mathrm{H}) .{ }^{13} \mathrm{C}$ NMR $(75$ $\left.\mathrm{MHz}, \mathrm{CDCl}_{3}\right): \delta=14.2,22.4,22.7,26.8,27.1,29.3,29.4,31.9$, $45.2,49.5,66.6,153.6$.

\section{6-Methyl-3-octyl-1,3-oxazinan-2-one (15)}

Yellow oil (0.378 g, $1.67 \mathrm{mmol}$, yield 17\%). ${ }^{1} \mathrm{H}$ NMR (300 MHz, $\left.\mathrm{CDCl}_{3}\right): \delta=0.62-0.66(\mathrm{~m}, 3 \mathrm{H}), 1.05-1.15(\mathrm{~m}, 10 \mathrm{H}), 1.12-1.14(\mathrm{~d}$, $J=6.3 \mathrm{~Hz}, 3 \mathrm{H}), 1.51-1.60(\mathrm{~m}, 2 \mathrm{H}), 1.76-1.80(\mathrm{~m}, 1 \mathrm{H}), 1.81-1.84$ $(\mathrm{m}, 1 \mathrm{H}), 2.92-3.21(\mathrm{~m}, 4 \mathrm{H}), 4.08-4.19(\mathrm{~m}, 1 \mathrm{H}) .{ }^{13} \mathrm{C}$ NMR $(75$ $\left.\mathrm{MHz}, \mathrm{CDCl}_{3}\right): \delta=14.3,21.1,22.8,26.9,27.3,29.2,29.4,29.5$, 32.0, 44.6, 49.4, 73.5, 153.8. HRMS: $m / z$ calcd for $\mathrm{C}_{13} \mathrm{H}_{25} \mathrm{NO}_{2}+\mathrm{H}^{+}$: 224.1287; found: 224.1300 .

Supporting Information for this article is available online at http://www.thieme-connect.com/ejournals/toc/synlett.

\section{References and Notes}

(1) (a) Ghosh, A. K.; Bilcer, G.; Schiltz, G. Synthesis 2001, 2203. (b) List, B.; Castello, C. Synlett 2001, 1687. (c) Fuchs, K.; Eickmeier, C.; Heine, N.; Peters, S.; Dorner-Ciossek, C.; Handschuh, S.; Nar, H.; Klinder, K. US 2010144681 A1, 2010.

(2) Berger, R.; Chang, L.; Edmonson, S. D.; Goble, S. D.; Harper, B.; Kar, N. F.; Kopka, I. E.; Li, B.; Morriello, G. J.; Moyes, C. R.; Shen, D. M.; Wang, L.; Wendt, H.; Zhu, C. WO 2009123870 A1, 2009.

(3) Li, Y.; Yao, W.; Rodgers, J. WO 200964835 A1, 2009.

(4) Ali, A.; Sinclair, P. J.; Taylor, G. E. US 2009018054 A1, 2009.

(5) Tomokazu, H.; Yasuko, Y.; Toshihiko, S.; Koki, M. EP 2085392 A1, 2009.

(6) (a) Fujiwara, M.; Baba, A.; Matsuda, H. J. Hetrocycl. Chem. 1989, 26, 1659. (b) Shibata, I.; Nakamura, K.; Baba, A.; Matsuda, H. Bull. Chem. Soc. Jpn. 1989, 62, 853.

(7) (a) Jung, J.; Avery, M. A. Tetrahedron Lett. 2006, 47, 7969. (b) Wang, G.; Ella-Menye, J.; Sharma, V. Bioorg. Med. Chem. Lett. 2006, 16, 2177. (c) Trifunovic, S.; Dimitrijevic, D.; Vasic, G.; Vukicevic, R. D.; Radulovic, N.; Vukicevic, M.; Heinemann, F. W. Synthesis 2010, 943.

(8) (a) Kayaki, Y.; Mori, N.; Ikariya, T. Tetrahedron Lett. 2009, 50, 6491. (b) Rice, G. T.; White, M. C. J. Am. Chem. Soc. 2009, 131, 11707. (c) Nahra, F.; Liron, F.; Prestat, G.; Mealli, C.; Messaoudi, A.; Poli, G. Chem.-Eur. J. 2009, 15, 11078. (d) Mangelinckx, S.; Nural, Y.; Dondas, H. A.; 
Denolf, B.; Sillanpaa, R.; De Kimpe, N. Tetrahedron 2010, $66,4115$.

(9) (a) Kim, Y. J.; Varma, R. S. Tetrahedron Lett. 2004, 45, 7205. (b) Ella-Menye, J.; Sharma, V.; Wang, G. J. Org. Chem. 2005, 70, 463.

(10) McElroy, C. R.; Aricò, F.; Benetollo, F.; Tundo, P. Pure Appl. Chem. 2012, 84, 707.

(11) Tundo, P.; Selva, M. Acc. Chem. Res. 2002, 35, 706.

(12) Benzylamine $(0.16 \mathrm{~g}, 1.5 \mathrm{mmol})$, propane-1,3-diol (0.12 g, $1.5 \mathrm{mmol})$, di-tert-butyl carbonate $(0.79 \mathrm{~g}, 4.5 \mathrm{mmol})$, and $\mathrm{KO}$ - $\mathrm{Bu}(0.34 \mathrm{~g}, 3 \mathrm{mmol})$ were reacted at $90{ }^{\circ} \mathrm{C}$ for $2 \mathrm{~h}$; the only product of the reaction was a small quantity of dibenzyl urea.
(13) Tundo, P.; McElroy, C. R.; Aricò, F. Synlett 2010, 1567.

(14) Tundo, P.; Aricò, F.; Rosamilia, A. E.; Rigo, M.; Maranzana, A.; Tonachini, G. Pure Appl. Chem. 2009, 81, 1971.

(15) 3-Benzyl-6,6-dimethyl-1,3-oxazinan-2-one (3) was isolated by combining the reaction products from entries 2-4 (Table 3) prior to column chromatography. Due to many byproducts having similar $R_{f}$ values to that of $\mathbf{3}$, only a small amount was isolated.

(16) Product 4 was attributed to this low yield compound as HPLC retention time and GC-MS data were consistent with such an oxazinanone. 